\title{
Specifics of professional health of teachers
}

\author{
T.V. Gudina ${ }^{1 *}, V . N$. Ponikarova ${ }^{2}$, and N.V. Starovoit ${ }^{3}$ \\ ${ }^{1}$ Cherepovets State University, Cherepovets, Russia \\ ${ }^{2}$ Cherepovets State University, Cherepovets, Russia \\ ${ }^{3}$ Baltic Federal University, Kaliningrad, Russia
}

\begin{abstract}
The article considers and describes in detail the peculiarities of teachers' professional behavior. The authors determine its most specific and essential features, as well as its structure depending on the type of educational organization and region of residence. Besides, a significant part of the research is devoted to the consideration and comparison of teachers' professional behavior characteristics depending on the level of occupational health disorders. The experimental study involved the teachers who implement inclusive education in the Northwestern Federal District of the Russian Federation (Kaliningrad and Vologda regions). Among them there are future teachers and secondary school teachers implementing inclusive practice, preschool and secondary school teachers working with the children with disabilities. The total amount of the participants was 1450 people, and the number of representative samples came up to 752 people. In the course of the study, the role of various factors in teachers' professional behavior was revealed and updated: behavioral and environmental factors as well as personality traits. In order to maintain professional health of teachers, a psychological and pedagogical workshop was organized, which included educational and applied stages. In modular psychological and pedagogical support, the emphasis was made on health-saving technologies that contribute to professional burnout prevention, on the possibility of developing and applying relevant patterns of coping behavior in labor relationships.
\end{abstract}

\section{A problem statement}

Modern pedagogical process organization presupposes an increase in the share of educational institutions in which a universal barrier-free environment has been created, which makes it possible to provide effective education for the disabled and people with normotypic development. The relevance of the designated course is determined by global trends, within which the modernization of public education systems is focused on ensuring the rights and freedoms of students, regardless of their race, religion and developmental disabilities [1,2].

In modern Russia, there is an urgent need to provide state educational institutions (preschools, secondary schools, vocational and higher educational institutions, supplementary educational institutions) with teachers professionally equipped for the

${ }^{*}$ Corresponding author: prof-ped.gpa@mail.ru 
implementation of inclusive education of people with disabilities (HL), possessing the appropriate professional qualities and competencies and capable of meeting special educational needs and arranging special conditions. In its turn, it determines the success of solving one of the most pressing issues of modern society, that is not only ensuring the socialization and adaptation of people with disabilities, but also training efficient teaching staff capable of implementing these solutions [3].

Changing paradigms, growing inclusiveness of educational space, openness leading to the coexistence of various models and technologies of education, dramatically change the idea of significant professional characteristics of a modern teacher: readiness for professional activity, a set of professional qualities, a high level of professional competence, etc.

At the same time, inclusive education implementation often requires from the teacher not only dedication, work at the limit of mental and physical strength, personal selfdevelopment, but also good health, endurance, emotional balance, and frustration tolerance.

The categories of norm and pathology, health and disease are often the main vectors that set the criteria for assessing a person's condition in any profession. In this case, the norm category is used as a basic criterion for comparing the current (actual) and permanent (usual) health condition [4].

At the social level, norms and pathologies (disorders) are determined as diseases as a lack of health, and health as an absence of disease [5].

Health is a dynamic process, a decrease in its quality entails a third state, in which a pathological process is possible due to a decrease in adaptation reserves. Thus, it is relevant to understand that health is an essential condition for success in any field, including teacher's professional activity [6].

\subsection{The objective of the work}

Based on the above provisions, it can be noted that there is a definite contradiction between the high requirements for the implementation of inclusive practice and the ability of teachers to implement it without any damage to their own health and the health of other participants in the inclusive process.

In connection with the above, we have determined the purpose of the research: to identify teachers' professional health peculiarities depending on the type of educational organization, as well as on the region of residence.

The subject of the research is professional health of teachers.

As a general hypothesis, the following assumption is made: professional health of a teacher is a complex multi-component structure that includes a number of aspects cognitive, social, personal, behavioral and emotional.

Professional health of teachers will be maintained and monitored if the following conditions are met:

- screening diagnostic program development and implementation to study teachers' professional health;

- determining the factors contributing to teachers' professional health maintenance in the process of implementing inclusive education;

- possibilities of making the ways of individual and personal development of a teacher as a subject of inclusive practice;

- the use of a number of health-preserving and educational technologies for professional health of teachers.

To solve the tasks and test the hypothesis, the following research methods were used:

1. Theoretical research methods: interdisciplinary analysis and synthesis of concepts and ideas of philosophical, pedagogical, medical, psychological, economic, sociological, 
methodological literature and normative documents on research problems; generalization, comparison, abstraction, modeling, forecasting, design of systems and processes, systemic, structural (functional) and integrated approaches.

2. Empirical research methods: observation, questioning, interviewing, psychological experiment, expert assessment, analysis of regulatory documents and experimental materials, mathematical methods of processing the data obtained using the " $\chi 2$ " - Pearson criterion, ranking method, Spearman's rank correlation coefficient, factorial analysis.

The total amount of the participants was 1450 people, and the number of representative samples came up to 752 people.

They include the teachers who implement inclusive education on the territory of the Northwestern Federal District of the Russian Federation (Kaliningrad and Vologda regions). Among them there are future teachers - $13 \%$ and secondary school - $36 \%$ (Kaliningrad region), preschool teachers (PS) - 27\% and teachers of general education schools for children with disabilities $-24 \%$ of the respondents (Vologda region).

To study the features of teachers' professional health, we have used a complex of express diagnostics complementary methods.

Express diagnostics includes an expert assessment of a behavior type in a professional environment (according to Schaarschmidt U., Fischer A.W.) [7], a questionnaire for identifying individual coping strategies (according to E. Heim) [8], a questionnaire "Risk factors of professional activity" (according to E.V. Zmanovskaya, adapted by us) [9], the questionnaire "Symptoms of professional burnout" (according to N.E. Vodopyanova, adapted by us) [10], the test "Self-assessment of mental conditions" (according to G. Eysenck) [11] and others.

\section{Results of the research}

Express diagnostics allows conducting a screening study of professional health peculiarities of future teachers and the teachers who implement inclusive educational practices in various educational institutions.

The state of respondents' professional health was assessed in terms of their resistance to stress, professional burnout and professional deformation: high level of risk, middle level of risk and low level of risk.

High level of risk is understood as a serious deviation from the normative indicators of professional health, middle level of risk corresponds to the third condition, and low level of risk, in general, meets the norm requirements $[12,13]$.

The obtained data analysis allows stating that the number of participants with a high level of risk is slightly more than a third of the studied samples (31\%).

This group of respondents is characterized by low and moderate importance of professional activity. Frustration tolerance is predominantly reduced; pronounced symptoms of emotional and professional burnout as well as predominance of reduction and depersonalization phenomena are clearly defined. The behavior is characterized by constant sense of anxiety and pointless fear. There is a paradoxical combination of actions aimed at giving up activities in case of failure and excessive offensiveness in solving problems. The leading occupational risk factors are predominance of negative emotions and experiences, increased physical and affective stress in practical activity. A narrow, rigid, inadequate set of coping behavior patterns with a predominance of avoidance strategies in the form of a search for a minus compromise, seeking help, cooperation, is characteristic for this group of respondents.

The number of respondents with a middle level of risk was $16 \%$.

These teachers are characterized by adequate performance of professional duties. The importance of professional activity is moderate. Frustration tolerance is average; emotional 
and professional burnout formation and the predominance of depersonalization symptoms are defined. Some predominance of negative emotions can be noted as a result of mental overload, striving for perfection and dissatisfaction with their activities.

The teachers of this group are characterized by moderate offensiveness in solving problems related to pedagogical activity. The leading occupational risk factors for the respondents are overly intense communication and information overload in their professional activity. The teachers revealed a fairly adequate use of coping behavior patterns in problem situations caused by pedagogical activity; they prefer to use interaction strategies in solving the problem, as well as plus-compromise strategies. Difficulties in mastering new styles of behavior are noted, which manifests itself in the application of the same type of coping patterns in various situations.

The largest subgroup is formed by respondents with a low level of risk - 43\%. These teachers are characterized by successful professional performance. The leading occupational risk factors for this group are extreme situations in work activity with the relevant use of coping behavior patterns, as well as a high degree of responsibility, which is combined with high and medium frustration tolerance. A pronounced (sometimes excessively) aggressiveness in solving problems is characteristic of these teachers. The preference is given to the strategies of effective interaction, and the failures are considered as an incentive to search for active strategies to overcome them.

A comparative analysis of the data of respondents from different educational organizations has made it possible to note that the largest number of the participants with a high level of risk is represented by the students (42\%) and teachers of secondary schools implementing inclusive practice (39\%).

The respondents with middle level of risk are mostly preschool teachers $(36 \%)$. The respondents with a low level of risk are from general education schools for children with disabilities.

The use of the $\chi^{2}$ (chi-square) criterion shows statistically significant differences between the teachers of different strata, which were observed among preschool teachers and teachers of general education schools for children with disabilities $(\chi 2=68.49$, significant for $\rho \leq 0.01)$, as well as between future teachers and teachers of general education schools for children with disabilities $(\chi 2=53.34$, significant for $\rho \leq 0.01)$.

In our research, we have paid special attention to the study of work behavior in a professional environment $[14,15]$.

Analyzing the results, it can be noted that a frugal type of work behavior is typical for the majority of the respondents. It is characterized by average level of motivation, energy costs, professional aspirations, capability of maintaining a distance in relation to professional activity, satisfaction with work results. A distinctive feature of this type is general satisfaction in life, resulting from the experience not related to work. As we have noted, it is typical for the students and preschool teachers with middle level of risk [8-10].

The next type is optimal possessing an active message to action, capable of solving difficult problems, constructively overcoming conflict situations and failures. Failures are viewed not as a source of negative emotions, but as an incentive to find effective strategies to overcome them. The teachers of this behavior type prioritize work, but at the same time control their own energy costs. These peculiarities in behavior are typical mainly to the secondary school teachers who work with disabled children and demonstrate a low level of risk.

A high level of risk behavior is characterized by an extremely high subjective attitude to professional activity, overestimated readiness for energy expenditures, low resistance to frustration and stress. The predominance of negative emotions, as a result of mental overload, striving for excellence and the associated dissatisfaction with their activities, was 
revealed mainly among teachers of secondary schools who implement inclusive practice and have a middle level of risk and a high level of risk.

A burnout type of behavior in a professional environment was demonstrated mainly by the teachers of secondary schools implementing inclusive practice who were referred to high level of risk. The following peculiarities are characteristic of them: extreme attitude to work, difficulties in the rational distribution of efforts in the performance of their professional duties.

Thus, of the considered behavior types, the optimal type of work behavior is more common $(31 \%)$.

The use of Spearman's rank correlation coefficient has made it possible to note statistically significant results obtained when comparing the students and teachers of secondary schools implementing inclusive practice $(\mathrm{r}=0.75, \rho \leq 0.01)$, as well as between teachers of inclusive secondary schools and teachers of secondary schools for children with disabilities $(r=0.73, \rho \leq 0.01)$.

The comparative study of the qualities of work behavior in a professional environment by the regional factor showed that among the teachers of the Kaliningrad region, such qualities as personal significance of professional activity, the perfection of their competencies, balance and support of colleagues are considered to be of the highest ranks.

For the teachers of Vologda region, high rank qualities are the need to support relatives and colleagues, balance, readiness for a significant consumption of energy in professional activities.

Factor analysis of the data shows that the most significant factors of occupational health in the studied group are occupational risk factors (specific weight 20), coping strategies (specific weight 17) and anxiety (specific weight 16). The factor with the smallest specific weight is rigidity (7).

For the students, the most significant factor is coping strategies (23), for the preschool teachers it is frustration (21), for the secondary school teachers this factor is the type of behavior in a professional environment, for the teachers of secondary schools for children with disabilities - professional risk factors (24).

Thus, the group of significant factors that determine the professional health of teachers depending on the educational organization includes, first of all, behavioral, environmental factors and only then personality traits.

The comparison carried out according to the regional criterion also allows us to note that among the teachers of Kaliningrad region, the respondents with a high level of risk prevail (41\%), while among the teachers of Vologda region there are more respondents with a low level of risk $-51 \%$. The number of respondents with a middle level of risk is approximately the same -29 and $26 \%$.

The use of the chi-square test shows that statistically significant differences were obtained between the indicators of professional health of Kaliningrad and Vologda regions $-\chi 2=22.91$, significant at $\rho \leq 0.01$.

The comparison by occupational health factors makes it possible to see that among the teachers of the Kaliningrad region, coping strategies (20), type of behavior in a professional environment (17) and occupational risk factors (16) are the most important.

For the teachers of Vologda Oblast, the most significant are professional risk factors (20), frustration and rigidity (16).

Thus, comparing the teachers of the two regions, it can be stated that for Kaliningrad region teachers the most significant factors are behavioral factors, while for the teachers of Vologda region - those associated with personal qualities. The general factors that determine the structure of teachers' professional health are occupational risk factors.

The results obtained have made it possible to outline and carry out a number of activities aimed at shaping the professional behavior of teaching staff $[16,17,18]$. 
So, for the students and teachers of secondary schools implementing inclusive practice, on the basis of the Immanuel Kant Baltic Federal University and the Cherepovets State University, a psychological and pedagogical workshop was organized, including educational and applied stages and modular psychological and pedagogical support [19, $20]$.

At the educational stage of the workshop, the ideas about the formation of a teacher's professional health were put forward.

The applied stage was a system of practical lessons (trainings), consisting of three levels: tentative, basic and consolidating.

The aim of the tentative level was to unite the group members and to study their psychological problems. The thematic training "Seed" aimed at increasing the psychological competence of a specialist in the field of inclusive education was conducted.

At the reconstructive level, two thematic trainings were carried out: "Inflorescence", which goal was to realize the teachers' own personal achievements related to the individual characteristics of professional health, and "Sprout" training aimed at preventing psychological and professional problems, resolving crisis situations in the practice of inclusive education.

The consolidating level was distinguished by the thematic training "Flowers" with its feature to prevent professional burnout.

Psychological and pedagogical support of the teachers included:

- Diagnostic module, including professional health diagnosis, carried out within the framework of a general psychologist and clinical psychologist's activities;

- Design module includes the definition of goals, directions, tasks, methods, mechanisms, principles of support and joint activities of all specialists;

- The support implementation module contains the joint activities of all specialists, but with the differentiation of its types. Thus, psychological counseling is carried out by a clinical psychologist; psychological training is carried out by a psychologist and a clinical psychologist; psychological correction - by a clinical psychologist, biofeedback therapy specialists and a rehabilitologist; psychological education and prevention - by all specialists;

- The reflexive module plans determining the tracking results.

\section{Conclusions}

To conclude, we have developed and implemented a screening study program for the professional health of teachers.

It had been revealed that the students and teachers of general education schools who implement inclusive practice demonstrate the most unfavorable indicators of professional health. The most significant differences in the structure of the studied definition were characteristic of preschool teachers and the teachers of general education schools for children with disabilities.

Based on the analysis, it was concluded that the teachers' professional health also depends on the region of residence and indicates the predominance of behavioral factors as system-forming feature of professional health of Kaliningrad region representatives, while for Vologda region teachers, such factors are personality traits.

The influence of educational organization type on the considered category has been determined; it can be noted that the group of essential factors includes, first of all, behavioral, environmental factors, and only then personality traits.

To maintain the professional health of teachers, psychological and pedagogical support was offered, and the emphasis was placed on health-saving technologies that contribute to the prevention of burnout, the possibility of developing and applying relevant patterns of 
coping behavior in labor relationships. The proposed module can be applied within the framework of advanced training courses for teachers of all educational levels.

\section{References}

1. G.V. Akhmetzhanova, A.A. Stepanko, Preparing a future teacher for work in inclusive education: a motivational aspect, 7, 1 (22), 181-184 (2018)

2. B.B. Aismontas, S.V. Panyukova, G.G. Saitgalieva, Educational and methodological support of teaching students with disabilities at the university, 22 (1), 60-70 (2017)

3. I.A. Bukina, O.A. Denisova, V.N. Ponikarova, Inclusive Education, 162 (2016)

4. S.L. Solovyova, Criteria for the norm in clinical psychology, 3 (26) (2014)

5. B.B. Ismontas, M.A. Odintsova, Socio-psychological support of students with disabilities and disabilities, 22 (1), 71 (2016)

6. G.V. Zalevsky, Clinical Psychology and Health Psychology, 3, 352 (2013)

7. U. Schaarschmidt, A.W. Fischer, AVEM - ein diagnostisches Instrument zur Differenzierung von Typen gesundheitsrelevanten Verhaltens und Erlebens gegenuber der Arbeit, 18 (3),15-163 (1997)

8. Heim E., Coping und Adaptivitat: Gibt es geeignetes oder ungeeignetes Coping, Psychother., Psychosom., med. Psychol, 1, 8-17 (1988)

9. N.E. Vodopyanova, E.S. Starchenkova, Burnout syndrome, 343 (2017)

10. N.V. Starovoit, V.N. Ponikarova, Formation of inclusive readiness of future teachers: model, directions, technologies, 50. (2021)

11. H.J. Eysenck, S.G.B. Eysenck, The Eysenck Personality questionnaire, 34 (1975)

12. N.V. Starovoit, Teacher of an inclusive school in terms of professional requirements, research and practice, 1 (43), 180-184 (2018)

13. S.Yu. Volchenko, Implementation of additional professional education programs for university staff on inclusive education: the experience of the Novosibirsk State Technical University, 1, 78-80 (2018)

14. O.A. Denisova, T.V. Gudina, I.A. Bukina, L.A. Antonova, The role of regional higher education institutions in creating conditions for people with disabilities in inclusive educational environment of the Russian Federation, 9(37) (2016)

15. L.A. Antonova, Developing the methodological support for specialists training in inclusive education, 30. (2017).

16. O.A. Denisova, T.V. Gudina, O.L. Lekhanova, V.N. Ponikarova, Features of the training of teaching staff who carry out inclusive practice, 4, 222-233 (2020)

17. V.N. Ponikarova, Dynamics of teachers' readiness for inclusive education: stages, features and trends, 122 (2019)

18. V.V. Degtyareva, Universal design of the educational space of a university in the context of the implementation of an inclusive educational policy, 1, 111-114 (2018)

19. Comprehensive support of education and professional development of people with disabilities and persons with disabilities: materials of the International Scientific and Practical Conference, 313 (2016)

20. A.O. Budarin, N.V. Starovoit, Socio-cultural practices in the training of teachers of inclusive education: the experience of Immanuel Kant IKBFU, 6, 130-139 (2018) 